down near the bladder, where the small bowel, three feet from the cecum, was adherent to the anterior abdominal wall. Within this adherent bowel the nails could be felt running forward to the abdominal wall and firmly fixed thereto. On breaking up the adhesions the larger nail was left behind firmly fastened in the abdominal wall by its point, while its head was still within the gut. This nail was pushed back, loosened and removed, and the opening in the gut sutured. The other nail had been displaced some eight inches toward the cecum, but was easily found and removed (Fig. $3)$. The whole abaomen was explored by the introduceu hand, and no other foreign boaies could be found. The stomach was examined with special care, and no evidences of induration or dilatation were discovered.

Postoperative History.-Recovery was uneventful except for a colon bacillus abscess which developed on the sixth day and opened through the lower corner of the incision, apparently arising from the abdominal wall at the site of the nail puncture.

The nails removed were not corroded like those previously removed from the stomach, showing that they had undoubtedly passed directly by gravity through the gastroenterostomy into the gut.

The points of interest in this case are:

1. The rarity of the localization of such foreign bodies in the ileum, they generally lodging in the stomach or passing therefrom directly to the cecum, or later into the sigmoid flexure or rectum.

2. The unique feature of the passage of the rather blunt nail through the gut wall and at least half an inch into the abdominal wall without causing peritonitis

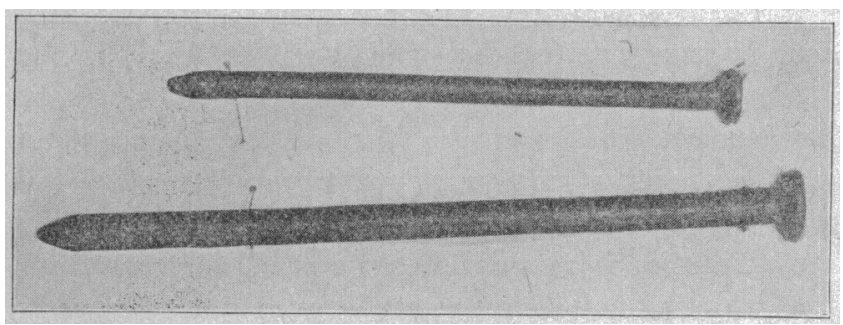

Fig. 3.-Nails removed from ileum, three-fourths natural size.

or even local abscess after remaining in situ for at least ten days.

3. The action of the gastroenterostomy in refusing harbor within the stomach to these nails, while before this operation all nails seemed to have been either retained or pessed per anum.

Since writing the above report the patient, who had passed into the hands of my successor at the City Hospital, Dr. J. W. Little, showed some symptoms of intestinal obstruction.

Third Operation.-For this a third laparotomy was done above the umbilicus, and as adhesions were numerous and the conditions. present obscure, a very long incision was finally made. No actual obstruction was found, but during the thorough examination a mass was discovered behind the stomach, apparently in the lesser peritoneal cavity and immediately in front of and adnerent to the great vessels. This was carefully dissected down on, and twent ${ }$-eight corroded nails were found imbedded in inflammatory tissue.

These nails had apparently escaped from the stomach by perforation, probably before the first operation, as there were no evidences at the later operations or in the history, of recent stomach disturbances. Also the patient is certain that but seven nails have been swallowed since the first operation. It is now thought that the abdomen, at least, is free from nails and other foreign bodies.

\section{A CASE OF ACTINOMYCOSIS OF THE PELVIS.*}

\author{
FRANK McMORROW, M.D. \\ SYRACUSE, N. Y.
}

Actinomycosis is a rare disease in this country, and the following case will be of interest. It presents all the salient features of this disease:

History.-Mrs. S. of East Syracuse, born of American parents; had always lived in the eity where her parents died at the ages of 75 and 78 ; one sister died during childbirth and one is living; three brothers are living, two have died, one as the result of an accident, the other of Bright's disease. She had always been strong and healthy up to the time of this sickness; usual weight 142 pounds. She was the innther of three healthy children, the youngest being five months old when she was first taken sick. Her food was that usual in the families of working people. About the middle of October, 1905, while ironing, she was seized with cramps in the abdomen. She sent for the family physician and after being in bed for a day was able to be about her work again. She had eaten some grapes that Jay and attributed her seizure in the abdomen to the fruit sile had taken: but from this time on she noticed her health began to fail. She had occasional attacks of vomiting which left her weaker each time; nothing that was done could check the progress of her malady. Abrut the first of Decentber she was confined to the bed continuously with constant vom. iting and general prostration. I saw her first December 26, She was much reduced in fiesh with a marked cachexia. I called her attention to a lump in her side; she said that she had felt it but as it gave her no pain or did not inconvenience her in any way she thought no more about it.

Examination.-On December 29, 1905, she was admitted to St. Joseph's Hospital, of this city in a toxic condition. Dr. A. B. Miller saw her in consultation with me. Her temperature was $101 \mathrm{~F}$., pulse 120 and she was very much prostrater and emaciated, the vomiting still continued and the bowels were very lcose. At times she was able to retain small amounts of animal broths and alhumin water. Physical examination showed that she was poorly nourished with cheeks sunken, complexion sallow and some abdominal tenderness. One mass was plainly discernible just to the left of the umbilicus and another in the left iliac fossa with areas which fluctuated on palpation. The liver and spleen were slightly enlarged. On vaginal examination a large tumefaction was felt, the physical signs of which denoted a pelvic abscess. The blood was examined; the red cells numbered $3,870,000$, the white cells 4350 . Hemoglobin was 37 per cent. The urine showed a specific gravity of 1.010 a trace of albumin, pus and a few round epithelial cells.

The patient's condition remained the same for three or four days; her temperature fluctuating between $99 \mathrm{~F}$. and $101.6 \mathrm{~F}$. The vomiting still persisted and there were from six to eight watery stools in 24 hours. On .January 6 , her condition not having improved, Dr. Miller opened the vaginal cul-de-sac and removed a large amount of fetid pus containing minute yellowish granules, a culture of which was sent to Dr. H. S. Steensland who promptly reported the infiammatory exudate taken from the cul-de-sac to contain Actinomyces.

The day following her temperature reached $102.6 \mathrm{~F}$. and her pulse 120 ; the vomiting ceased. In a few days the vomiting returned, less marked at first. She continued gradually to fail, growing weaker and being unable to retain any nourishment by the stomach she finally passed into a comatose condition, her temperature reaching 103.6 F. She died on the twenty-ninth day after entering the hospital.

* Read before the Syracuse Academy of Medicine, April 7, 1907.

Hunger Days in Diabetes.-Naunvn and Trson (Progressive Medicine) recommend "hunger davs" for diabetics. The occasional interposition of a day during which nothing but tea and bouillon are allowed is very wholesome. When the sugar in the urine has been reduced to a minimum, this practice not only causee the sugar to disappear, but increases the limits of tolerance thereafter. 